\title{
Turning obstacles into opportunity: experience of integrating point-of-care ultrasound into a first year medical school course
}

This article was published in the following Dove Press journal:

Advances in Medical Education and Practice

19 June 2013

Number of times this article has been viewed

\section{Tarina Lee Kang}

Department of Emergency Medicine, Los Angeles County and USC Medical Center, Los Angeles, CA, USA
Correspondence: Tarina Lee Kang I200 North State Street, Department of Emergency Medicine, Room I0I I, Los Angeles, CA 90033, USA Tel + I 3232267043

Email tarina.lee.kang@gmail.com

\section{Dear editor}

For over 100 years, medical schools throughout the United States have typically followed a standardized curriculum that clearly delineates the preclinical (basic and clinical sciences) and clinical years (patient encounters and care). ${ }^{1}$ However, the transfer of learning that is derived from isolated data of basic science to clinically relevant information has been a topic of much debate and study throughout the years.

Recently, educators have attempted to unite the preclinical and bedside principles in an effort to make the basic sciences more relevant to medical practice. Basic, clinical, and social sciences are taught simultaneously to reaffirm "the importance of the relationship between the practitioner and patient. Further, the practitioner should focus [on the patient] as a whole, be informed by evidence, and make use of all appropriate therapeutic approaches, health care professionals, and disciplines to achieve optimal health and healing."2 Although implementation of an integrated learning curriculum in medical school poses political, logistical, and financial challenges, its rewards for the student may be profound.

The ideal approach to integrating basic science material with the practice of medicine is complex in that educators often have to incorporate innovative and pertinent student experiences, without compromising the existing curriculum requirements. The sheer amount of information that first year medical students are required to learn makes inclusion of additive curriculum difficult. However, it behooves course directors to constantly test, change, and expand course curriculums to maximize the educational benefit to students.

There are a number of ways to implement clinical practice into the first year courses of medical school, with the theoretically most successful ones being those that can be brought to the student during class, where other students and instructors are present for more in-depth and collaborative discussion. Point-of-care ultrasound was developed by emergency physicians in an effort to better evaluate the patient at the bedside. More recently, ultrasound has become an important educational and clinical tool across all specialties due to its ease of use, portability, and applicability at the bedside. Many institutions have integrated bedside ultrasound teaching into the clinical years of medical school. Several US institutions such as Wayne State, Ohio State, and the University of South Carolina have implemented ultrasound curriculums that span from the first year to the entire 4 years of medical school..$^{3-5}$ In 2012 Fox et $\mathrm{al}^{6}$ at the University of California (Irvine, CA, USA) implemented a novel medical curriculum which integrated web-based 
lectures and peer instruction for Year I students. They were successfully able to maximize teaching and practice time and integrate practical medicine into the basic science courses. Given the success of these programs and the potential educational benefit they afford students, a seamless introduction of ultrasound into the first year courses at our affiliated medical school seemed like a natural progression.

The goal of the project was to integrate ultrasound, a practical clinical modality, into the preclinical educational experience, specifically, during the anatomy and histology classes and laboratory sessions. The ultrasound instructors successfully completed a 10-week course which combined anatomy and histology laboratory sessions, small group sessions, and lectures. After a year of planning, we successfully integrated ultrasound into the course in a way which emphasized how teaching in a dynamic and safe manner with the ultrasound can illuminate the structural relativity of human anatomy.

The novelty of this curricular change in a course that has never had this type of teaching before was itself an impediment. I think that, in retrospect, the adage "There is strength in numbers" is a proverb one should follow when attempting to implement a new course at a medical school. The more people you know who represent different specialties and ranks in both the hospital and the medical school, the higher the likelihood for continued success of the course.

When I started this project, I was naive to the accepted conduct and decorum that one is expected to follow when trying to introduce unprecedented ideas into the medical school curriculum. I had an idea worthy of pursuing, I created a plan to implement it, and I spoke to the directors of the course, but I did not attempt to gain crucial allies in the medical school who could have accelerated its acceptance. The legacy of new projects and teaching initiatives at medical schools will constantly be endangered unless there is consistent support at the administrative level. As a result, although I had the full support from the course directors, I did not have the complete acceptance of the laboratory professors and instructors who taught the course. This disconnection manifested in frustration and bewilderment by some students attending our course during their teaching time. In addition, because there was no formal explanation of our pilot to the students, some were unable to fully grasp the concept of an integrated educational forum, and noted on course feedback their lack of understanding as to why, and how, point-ofcare ultrasound correlates with anatomy and histology. This problem could have been curtailed, at least in some part, by a formal acknowledgment made by not only the course directors but also the administration. With this knowledge, we reached out to several medical school administrators, and we are in talks with them to gain valuable insight and input for further direction for next year's course. In addition, we are recruiting physicians from different specialties to broaden the type of expertise in our curriculum.

Although I encountered barriers, the experience was invaluable. It helped me understand, with startling clarity, the political structure of medical education. I have since moved to another academic medical center, and we are scheduled to begin talks to create an integrated curriculum with first year medical students. The next time I introduce myself though, I think I'll bring my friends.

\section{Disclosure}

The author reports no conflicts of interest in this communication.

\section{References}

1. Flexner A. Medical Education in the United States and Canada. A Report to the Carnegie Foundation for the Advancement of Teaching. Bulletin No 4. Boston, Mass: Updike. 1910.

2. Consortium of Academic Health Centers for Integrative Medicine. Kreitzer MJ, Kligler B Meeker W. Health Professions Education and Integrative Health Care. http://www.iom.edu/ /media/Files/Activity\%20 Files/Quality/IntegrativeMed/Health\%20Professions\%20Education\%20 and\%20Integrative\%20HealthCare.pdf. Accessed August 11, 2011.

3. Hoppmann R, Rao V, Poston MB, et al. An integrated ultrasound curriculum (iUSC) for medical students: a 4-year experience. Crit Ultrasound J. 2011;3(1):1-12.

4. Rao S, van Holsbeeck L, Musial JL, et al. A pilot study of comprehensive ultrasound education at the Wayne State University School of Medicine: a pioneer year review. J Ultrasound Med. 2008;27(5):745-749.

5. Butter J, Grant T, Egan M, et al. Does ultrasound training boost Year 1 medical student competence and confidence when learning abdominal examination? Med Educ. 2007;41(9):843-848.

6. Fox JC, Chiem AT, Rooney KP, Maldonaldo G. Web-based lectures, peer instruction and ultrasound-integrated medical education. Med Educ. 2012;46(11):1109-1110
Advances in Medical Education and Practice

\section{Publish your work in this journal}

Advances in Medical Education and Practice is an international, peerreviewed, open access journal that aims to present and publish research on Medical Education covering medical, dental, nursing and allied healthcare professional education. The journal covers undergraduate education, postgraduate training and continuing medical education

\section{Dovepress}

including emerging trends and innovative models linking education, research, and healthcare services. The manuscript management system is completely online and includes a very quick and fair peer-review system. Visit http://www.dovepress.com/testimonials.php to read real quotes from published authors. 